\title{
Similarities and differences between asthma and chronic obstructive pulmonary disease: treatment and early outcomes
}

\author{
A.S. Buist
}

\begin{abstract}
Similarities and differences between asthma and chronic obstructive pulmonary disease: treatment and early outcomes. A.S. Buist. C) ERS Journals Ltd 2003.

ABSTRACT: There are now many guidelines that provide direction for the diagnosis and management of asthma and chronic obstructive pulmonary disease (COPD). However, both diseases are still underdiagnosed (or misdiagnosed) and undertreated.

There is considerable evidence that treatment with anti-inflammatory drugs reduces morbidity and mortality in asthma. The evidence is growing regarding their effect on slowing the remodelling that occurs in subsets of asthmatics. COPD is more challenging. There are no disease-modifying drugs available yet that will change the natural history of COPD.

However, there is overwhelming evidence that smoking cessation will slow the progression of disease. Until better drugs are available for the treatment of COPD, emphasis must be placed on primary and secondary prevention by reducing exposure to noxious agents (cigarette smoke in particular).

Inhaled corticosteroids appear to have a place in the management of severe chronic obstructive pulmonary disease, perhaps by decreasing the frequency of exacerbations. Eur Respir J 2003; 21: Suppl. 39, 30s-35s.
\end{abstract}

Correspondence: A.S. Buist, Pulmonary and Critical Care Medicine, Oregon Health and Science University, 3181 SW Sam Jackson Park Road, UHN 67 Portland, OR 97239-3098, USA.

Fax: 15034946670

E-mail: buists@ohsu.edu

Keywords: Asthma, chronic obstructive pulmonary disease, detection, early treatment, prevention

Received: July 92002

Accepted after revision: October 92002
Until recently, the presence or absence of reversibility was thought to be the major distinction between asthma and chronic obstructive pulmonary disease (COPD), with reversible airflow obstruction being the hallmark of asthma and mainly irreversible airflow obstruction the hallmark of COPD. Over the past few years, the thinking about COPD has changed appreciably. Consequently, there are now new definitions for both asthma and COPD that acknowledge the overlap and highlight the similarities and differences between them. The key to this change in thinking has been the recognition that chronic inflammation underlies both diseases. The nature of the inflammation differs, however, as does the response to anti-inflammatory medications.

\section{Definitions}

\section{Asthma}

In the recent Global Initiative for Asthma (GINA) Guidelines [1] asthma is defined as follows: a chronic inflammatory disorder of the airways in which many cells and cellular elements play a role. The chronic inflammation causes an associated increase in airway hyperresponsiveness that leads to recurrent episodes of wheezing, breathlessness, chest tightness and coughing, particularly at night or in the early morning. These episodes are usually associated with widespread but variable airflow obstruction that is often reversible, either spontaneously or with treatment.

\section{Chronic obstructive pulmonary disease}

In the recent Global Initiative for Chronic Obstructive Lung Disease (GOLD) Guidelines [2], COPD is defined as follows: a disease state characterised by airflow limitation that is not fully reversible. The airflow limitation is usually progressive and associated with an abnormal response of the lungs to noxious particles or gases.

\section{Similarities and differences}

Asthma and COPD have important similarities and differences [3]. Both are chronic inflammatory diseases that involve the small airways and cause airflow limitation [4-9], both result from gene-environment interactions and both are usually characterised by mucus and bronchoconstriction.

The similarities are striking, but the differences are also striking. For example, different anatomical sites are involved [8]; COPD affects both the airways and the parenchyma, whilst asthma affects only the airways. Both asthma and COPD involve the small airways and the structural changes in the small airways are responsible for much of the physiological impairment that occurs in these diseases [10-12].

Perhaps the most important difference between asthma and COPD is the nature of inflammation, which is primarily eosinophilic and CD4-driven in asthma, and neutrophilic and CD8-driven in COPD $[1,2,13-15]$. This is a very important distinction 
because the nature of the inflammation affects the response to pharmacological agents. There is now ample evidence that inhaled corticosteroids are effective against the eosinophilic inflammation in asthma but largely ineffective against the primarily neutrophilic inflammation seen in COPD [16-18]. One fact not acknowledged in the definitions is that airway remodelling can occur in long-standing asthma [13, 19-22] and results in partially reversible airflow obstruction. Therefore, in many (but not all) patients with long-standing asthma there is a component of chronic irreversible airflow obstruction with reduced lung function and incomplete response to a short-acting bronchodilator or to an oral or inhaled corticosteroid. This makes the diagnosis of asthma sometimes challenging in older adults and it requires the adjustment of the goals of treatment with respect to the patient's age, as maintenance of normal lung function can no longer be a realistic goal.

It is also not often acknowledged that both diseases often co-exist in an individual, so it is not uncommon to see the characteristics of both diseases. It is therefore often challenging for the clinician to know which disease a patient has or what mix of diseases, since COPD is not one disease but rather a spectrum of diseases involving both the airways and parenchyma $[2,23]$.

Because of the differences in the cells involved in asthma and COPD, and the relative lack of efficacy of pharmaceutical agents that can alter the progression of COPD (disease-modifying), the approach to the treatment of asthma and COPD is different. The essential difference is that the treatment of asthma is driven by the need to suppress the chronic inflammation, whereas in COPD, treatment is driven by the need to reduce symptoms.

The treatment algorithm is based on severity for both asthma and COPD. For asthma, severity is based on symptom frequency and severity, lung function and healthcare utilisation [1]. For COPD, the stages of severity are defined by lung function [2].

\section{Staging and treatment of asthma}

The goals of long-term management of asthma should include the following: 1) achievement and maintenance of control of symptoms; 2) prevention of asthma exacerbations; 3) maintenance of pulmonary function as close to normal levels as possible; 4) maintenance of normal activity levels, including exercise; 5) avoidance of adverse effects from asthma medications; 6) prevention of the development of irreversible airflow limitation; and 7) prevention of asthma mortality.

The recommended GINA treatment algorithm, together with the clinical features and staging of severity of asthma, are available on the GINA website [1]. It is important to note that the forced expiratory volume in one second (FEV1) levels are before treatment, i.e. in the unmedicated state.

Until the advent of anti-inflammatory drugs, asthma was treated on an as-needed basis and treated as an acute disease rather than a chronic disease. With the recognition that asthma is a chronic inflammatory disease, there has been a gradual move towards treating it more aggressively and earlier in the hope that this may change the natural history of asthma and prevent some of the remodelling that sometimes occurs.

Since asthma therapy is guided by the need to control the inflammation, anti-inflammatory medications are the drugs of choice for all except mild intermittent asthma. The choice of treatment should be guided by the following: 1) severity of the patient's asthma; 2) the patient's concurrent treatment; 3) pharmacological properties and availability of the various forms of asthma treatment; and 4) economic considerations.

There has been fairly rapid uptake of the need for treating asthma as a chronic inflammatory disease. However, asthma is still undertreated for the most part. The ideal should be minimal or almost no use of rescue medications with control being maintained by anti-inflammatory drugs [24]. With this approach, the recognition that asthma control and asthma severity are conceptually distinct has emerged [24-26]. For example, although mild asthmatics have disease that is, by definition, relatively easy to control with rescue medications, they will occasionally suffer from acute exacerbations during which their level of control may be very poor. Similarly, individuals with moderate-tosevere asthma require more intensive treatment to control their symptoms, but with proper therapy they can experience good symptom control. From the perspective of the practicing clinician, level of control may be the more relevant measure because the objective of therapy will be to control symptoms and minimise the impact of the disease on patient functioning (i.e. to achieve a good level of control) [24]. Also, from the perspective of population-based disease management, asthma control could serve as a good indicator of the adequacy of healthcare provided to a population, as well as serving as an indicator of patients who may benefit from more aggressive management.

The clinician is faced with the question of how aggressively to treat a patient with asthma. Inherent in this question is the balance between the pros and cons of aggressive (and early) treatment. The argument in favour of early treatment is that it may reduce (or possibly prevent) the remodelling that occurs in asthma and allow lung growth and senescence to be normal.

The significance of the subepithelial fibrosis in asthma is not clear [20,21]. The correlation with asthma duration is good but the correlation with asthma severity is poor. The reason why there is so much interest and focus at present on the remodelling in asthma is the hope that early aggressive treatment, before subepithelial fibrosis is established, may change the natural history of asthma [27-29].

\section{Staging and treatment of chronic obstructive pulmonary disease}

The stages of COPD are defined primarily by lung function [2]. This emphasises the important clinical 
message that the diagnosis of COPD requires the measurement of lung function. The stages of COPD suggested in the GOLD Guidelines [2] are as follows. Stage 0: At risk, cough or sputum present but lung function normal. Stage 1: Mild COPD, FEV1/forced vital capacity (FVC) $<70 \%$, with an FEV $1 \geqslant 80 \%$ predicted, with or without chronic symptoms. Stage 2: Moderate COPD, FEV $1 / \mathrm{FVC}<70 \%$ and FEV $1 \%$ pred $>30 \%$ and $<80 \%$. Stage 2 is split at an FEV1 of $50 \%$ pred since the existing data support the value of inhaled corticosteroids below an FEV 1 of $50 \%$ pred but not above. Stage 3: Severe COPD, FEV1 <30\% pred and $\mathrm{FEV} 1 / \mathrm{FVC}<70 \%$.

In the GOLD guidelines, Stage 0 is a newly defined stage that was included to give a strong public health message that symptoms of chronic cough and sputum production should alert the clinician to the presence of an ongoing pathophysiological process even when lung function is normal. This may progress to clinically significant COPD in a proportion of those exposed (in particular to tobacco smoke) [30]. The analogy that is perhaps most relevant is that mild hypertension in some but not all (or indeed the majority), with mild elevation of blood pressure will progress to clinically significant hypertension.

The treatment goals for COPD [2] are as follows: 1) the prevention of disease progression; 2) the relief of symptoms; 3) improvement in exercise tolerance; 3) improvement in health status; 4) the prevention and treatment of exacerbations; 5) the prevention and treatment of complications; 5) a reduction in mortality; and 6) minimisation of side-effects from treatment.

As already emphasised, the approach to the management of COPD is driven by the need to control symptoms [2]. At all stages, every attempt should be made to reduce exposure to risk factors, including the following. 1) Avoiding noxious agents, including tobacco smoke, indoor air pollution and occupational exposures. The key strategy here is to encourage smoking cessation. 2) Reducing the impact of asthma exacerbations. The most effective preventive approach is to ensure annual influenza vaccination.

The striking effect of smoking cessation on slowing the progression of COPD has been illustrated vividly by the Lung Health Study (LHS-1), shown in figure 1 $[31,32]$. In this 5-yr study involving almost 6,000 smokers with mild-moderate COPD over the 5-yr follow-up, those who continued to smoke had a decline in FEV1 of $\sim 60 \mathrm{~mL} \cdot \mathrm{yr}^{-1}$. Those who were consistent quitters over the same period showed, on average, a small increase in FEV1 followed by a dramatically slowed rate of decline of FEV1 of $\sim 30 \mathrm{~mL} \cdot \mathrm{yr}^{-1}$.

There is ample evidence that brief interventions have an appreciable impact on smoking cessation rates [33-36]. The approach that is recommended is called the five "A's" as follows. Ask: systematically identify all tobacco users with every visit. Advise: strongly urge all tobacco users to quit. Assess: determine willingness to make quit attempt. Assist: aid the patient in quitting. Arrange: schedule follow-up contact.

Bronchodilator medications are central to the symptomatic treatment of COPD [2]. They are given on an as-needed basis, or regular basis, to prevent or

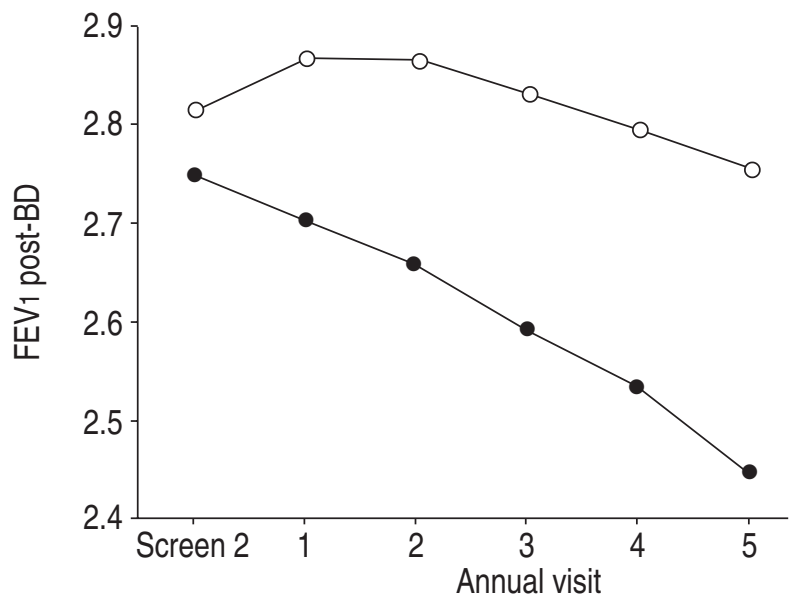

Fig. 1.-Mean postbronchodilator (post-BD) forced expiratory volume in one second (FEV1) for participants in the smoking intervention and placebo groups who were sustained quitters $(O)$ and continuous smokers $(\mathbf{O})$. The two curves diverge sharply after baseline. Reproduced with permission from [31].

reduce symptoms. The principal bronchodilator treatments are $\beta_{2}$-agonists, anticholinergics, theophylline and a combination of these drugs. The choice between $\beta_{2}$-agonists, anticholinergics, theophylline or a combination of therapy depends on the individual response (in terms of symptom relief and side-effects), the availability of the drugs and their cost. As with asthma, combining bronchodilators with different actions, e.g. $\beta$-agonists and anticholinergics, may improve efficacy and decrease the risk of side-effects compared to increasing the dose of a single bronchodilator.

The place of inhaled corticosteroids in the management of COPD has long been controversial. The GOLD guidelines recommend that inhaled corticosteroids be used in stages $2 \mathrm{~B}$ and 3 , i.e. when the FEV1 is $<50 \%$ pred and the patient has repeated exacerbations requiring treatment of antibiotics and/or oral glucocorticosteroids. The basis for this recommendation is that inhaled corticosteroids have not been shown to change the rapid decline of FEV1 in COPD. This result is consistent across four major clinical trials [37-40]. Inhaled corticosteroids can, however, reduce the frequency of exacerbations in individuals with frequent exacerbations [41]. They can also reduce the bronchial hyperresponsiveness associated with COPD [40] and may decrease mortality from COPD [42].

\section{Assessing outcomes in asthma and chronic obstructive pulmonary disease}

\section{Asthma}

The clinical benefits of inhaled corticosteroids in asthma include a decrease in airway hyperresponsiveness, an improvement in lung function and a reduction in severity of symptoms, frequency of exacerbations, the need for rescue medication, hospitalisation and asthma deaths, and an increase in symptom-free days [1]. There is strong evidence that treatment of antiinflammatories improves asthma control and reduces 
bronchial hyperresponsiveness [17-19, 43]. This can be illustrated by following weekly peak expiratory flow in the morning and evening following the initiation of inhaled corticosteroids The time course of reducing airway hyperresponsiveness may be months rather than weeks [24] (fig. 2). Night-time symptoms respond first, followed by FEV1, morning peak flow and, considerably later, airway hyperresponsiveness.

The important question of whether treatment with anti-inflammatories changes the natural history of asthma, especially in children, is still unresolved. Perhaps the best information comes from the Childhood Asthma Management Program (CAMP) carried out in the USA, in which lung function in children aged 5-12 yrs was followed over a period of 4-6 yrs [43]. A total of 311 of the children were on inhaled corticosteroids and 418 on placebo. The CAMP Study showed that inhaled corticosteroids improve asthma control in children with mild-tomoderate asthma, together with an improvement in pre-bronchodilator FEV1, reduced airway hyperresponsiveness, improvement in symptom scores and symptom frequency, fewer courses of corticosteroids and lower hospitalisation. However, inhaled corticosteroids did not change the post bronchodilator FEV1, which is considered to be a surrogate measure of lung growth (fig. 3). This was interpreted as evidence that inhaled corticosteroids do not affect lung remodelling, at least in the age range covered by the CAMP Study (5-12 yrs). This does not, of course, answer the question of whether the institution of inhaled corticosteroids before 5 yrs may have a different effect.

As noted above, there is increasing evidence that combining an inhaled corticosteroid with a longacting $\beta$-agonist can improve asthma control [44-46]. One large study that evaluated the effect of an inhaled corticosteroid and a long-acting $\beta$-agonist on exacerbations for asthma is the Formoterol and

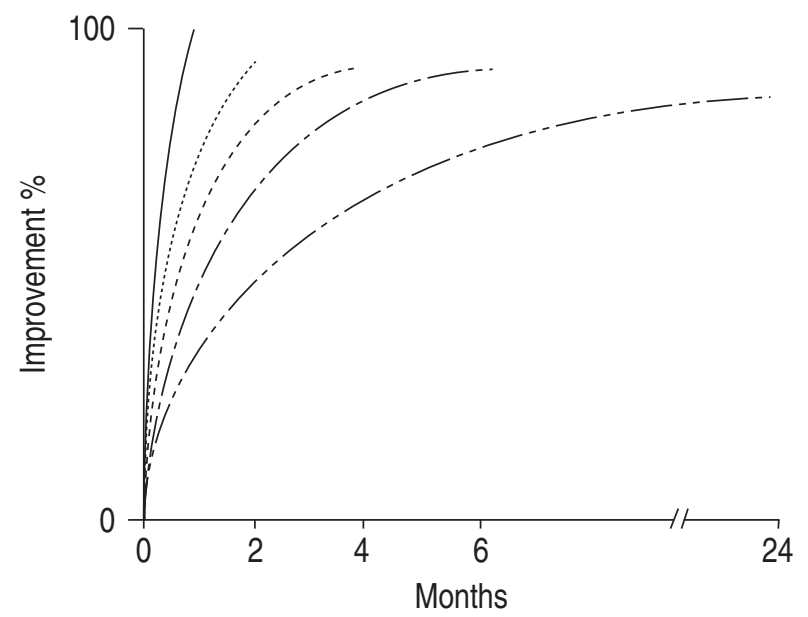

Fig. 2.-Rate of improvement in measures of asthma control with inhaled corticosteroid treatment, based on a clinical trial starting with high-dose budesonide. - : no night symptoms; $\cdots \cdot$ : forced expiratory volume in one second; -----: morning peak expiratory flow; --:: no short acting $\beta$-agonist use use; -..-: airway hyperresponsiveness. Reproduced with permission from [24].
Corticosteroids Establishing Therapy (FACET) study [47], in which 852 patients being treated with inhaled corticosteroids were randomly assigned to one of four treatments $(100 \mu \mathrm{M}$ budesonide plus placebo, $100 \mu \mathrm{M}$ budesonide plus $12 \mu \mathrm{M}$ formoterol, $400 \mu \mathrm{M}$ budesonide plus placebo or $400 \mu \mathrm{M}$ budesonide plus $12 \mu \mathrm{M}$ formoterol). Treatment was continued for $1 \mathrm{yr}$ and the outcomes followed were the frequency of exacerbations of asthma, symptoms and lung function in the four groups. The FACET Study reported that the rates of severe and mild exacerbations were reduced by $26 \%$ and $40 \%$, respectively, when formoterol was added to the lower dose of budesonide.

\section{Chronic obstructive pulmonary disease}

Up to this point, there are no disease-modifying drugs available that can change the natural history of COPD. Smoking cessation is the only intervention that has clearly been shown to be effective in slowing the accelerated rate of decline of lung function that is the hallmark of COPD. The LHS-1 explored the question of whether an anticholinergic bronchodilator, ipratropium bromide, would slow the rate of decline of FEV1 in COPD [31, 32]. It did not. Several years later, four large-scale clinical trials addressed the question of whether inhaled corticosteroids would slow the progression of COPD [31, 37-39]. All found that inhaled corticosteroids did not slow the rate of decline of lung function. However, the ISOLDE trial [39] showed that they did decrease the frequency of exacerbations in those with very low lung function and also slowed the relentless, rapid decline in health status in severe disease [41].

There is also some information from a retrospective database study using the administrative databases in Ontario, Canada, that inhaled corticosteroids may reduce morbidity and mortality in elderly patients [42]. Conversely, oral corticosteroids are associated

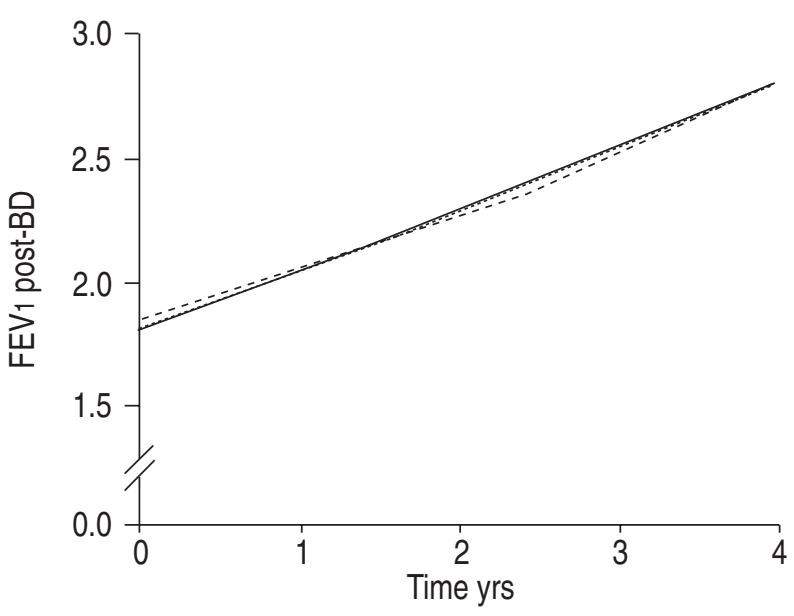

Fig. 3.- Mean values for forced expiratory volume in one second (FEV1), postbronchodilator (post-BD) 1-4 yrs of follow-up in the budesonide (----), nedocromil (…) and placebo (-) groups. The numbers of observations used to calculate means at annual intervals were as follows: $n=267-416$. Reproduced with permission from [43]. 
with increased mortality [2], probably because of steroid myopathy, which contributes to muscle weakness, decreased functionality and respiratory failure in advanced chronic obstructive pulmonary disease. Bursts of oral corticosteroids for treatment of acute exacerbations, however, shorten recovery time and help to restore lung function more quickly [48, 49].

\section{References}

1. Global strategies for asthma management and prevention, National Institutes of Health, National Heart, Lung, and Blood Institute. NIH Publication No 02-3659. 2002. www.ginasthma.com. Last updated: continuous. Last viewed: November 42002.

2. Global initiative for chronic obstructive lung disease. Global strategy for the diagnosis, management and prevention of chronic obstructive pulmonary disease NHLBI/WHO Workshop Report. NIH Publication No 2701. April 2002. www.gold.copd.com. Last updated: continuous. Last viewed: November 42002.

3. Buist AS. Definitions. Chapter 1. In: Asthma and COPD textbook; basic mechanisms and clinical management. Barnes P, Drazen J, Rennard S, Thomson N, eds. London, Academic Press, Elsevier Science Ltd., 2001.

4. Bousquet J, Jeffery PK, Busse WW, Johnson M, Vignola AM. From bronchoconstriction to airways inflammation and remodeling. Am J Respir Crit Care Med 2000; 161: 1720-1745.

5. Hamid Q, Song YL, Kotsimbos TC, et al. Inflammation of small airways in asthma. J Allergy Clin Immunol 1997; 100: 44-51

6. Martin RJ. Small airway and alveolar tissue changes in nocturnal asthma. Am J Respir Crit Care Med 1998; 157: 5188-5190.

7. Laitinen LA, Laitinen A, Altraja A, et al. Bronchial biopsy findings in intermittent or "early" asthma. J Allergy Clin Immunol 1996; 98: 53-56.

8. Jeffery PK. Structural and inflammatory changes in COPD: a comparison with asthma. Thorax 1998; 53: 129-136.

9. Barnes PJ. Chronic obstructive pulmonary disease. $N$ Engl J Med 2000; 343: 269-280.

10. Moreno R, Hogg JC, Pare PD. Mechanics of airway narrowing. Am Rev Respir Dis 1986; 133: 1171-1180.

11. James Al, Pare PD, Hogg JC. The mechanics of airway narrowing in asthma. Am Rev Respir Dis 1989; 139: 242-246.

12. Wiggs BR, Moreno R, Hogg JC, Hilliam C, Pare PD. A model of the mechanics of airway narrowing. $J$ Appl Physiol 1990; 69: 849-860.

13. O'Shaughnessy TC, Ansari TW, Barnes NC, Jeffery PK. Inflammation in bronchial biopsies of subjects with chronic bronchitis: inverse relationship of CD8+ T-lymphocytes with FEV1. Am J Respir Crit Care Med 1997; 155: 852-857.

14. Keatings VM, Collins PD, Scott DM, Barnes PJ. Differences in interleukin-8 and tumor necrosis factor- $\alpha$ in induced sputum from patients with chronic obstructive pulmonary disease or asthma. Am J Respir Crit Care Med 1996; 153: 530-534.

15. Saetta M, Di Stefano A, Turato G, et al. CD8+ $\mathrm{T}$-lymphocytes in peripheral airways of smokers with chronic obstructive pulmonary disease. Am $J$ Respir Crit Care Med 1998; 157: 822-826.

16. Haatela J, Jarvinen M, Kava T, et al. Comparison of $\beta_{2}$-agonist, terbutaline, with an inhaled corticosteroid, budesonide, in newly detected asthma. $N$ Engl J Med 1991; 325: 388-392.

17. Jeffery PK, Godfrey W, Adelroth E, Nelson F, Rogers A, Johansson SA. Effects of treatment on airway inflammation and thickening of basement membrane reticular collagen in asthma. Am Rev Respir Dis 1992; 145: 890-899.

18. Keatings VM, Jatakanon A, Worsdell YM, Barnes PJ. Effects of inhaled and oral glutocorticoids on inflammatory indices in asthma and COPD. Am J Respir Crit Care Med 1997; 155: 542-548.

19. Bousquet J, Jeffery PK, Busse WW, Johnson M, Vignola AM. Asthma. From bronchoconstriction to airways inflammation and remodeling. Am J Respir Crit Care Med 2000; 161: 1720-1745.

20. Ward C, Pais M, Bish R, et al. Airway inflammation, basement membrane thickening and bronchial hyperresponsiveness in asthma. Thorax 2002; 57: 309-316.

21. Chu HW, Halliday JL, Martin RJ, Leung DY, Szefler SJ, Wenzel SE. Collagen deposition in large airways may not differentiate severe asthma from milder forms of the disease. Am J Respir Crit Care Med 1998; 158: 1936-1944.

22. O'Donnell RA, Davies DE, Holgate ST. Airway remodeling. Chapter 7. In: Asthma and COPD Textbook. Barnes P, Drazen J, Rennard S, Thomson N, eds. 2002: 67-78. London, Academic Press, Elsevier Science Ltd., 2001.

23. Rennard SI. Inflammation and repair processes in chronic obstructive pulmonary disease. Am J Respir Crit Care Med 1999; 160: 512-516.

24. Woolcock AJ. Management of chronic asthma in adults. Chapter 64. In: Asthma and COPD Textbook. Basic Mechanisms and Clinical Management. Barnes P, Drazen J, Rennard S, Thomson N, eds. London, Academic Press, Elsevier Science Ltd., 2001.

25. Vollmer WM, Markson LE, $\mathrm{O}^{\prime}$ Connor $\mathrm{E}$, et al. Association of asthma control with health care utilization and quality of life. Am J Resp Crit Care Med 1999; 160: 1647-1652.

26. Vollmer WM, Marskson LE, $\mathrm{O}^{\prime}$ Connor E, Frazier AE, Berger M, Buist AS. Association of asthma control with health care utilization: A prospective evaluation. Am J Resp Crit Care Med 2002; 165: 195-199.

27. Olivieri D, Chetta A, Del Dono M, et al. Effect of short-term treatment with low-dose inhaled fluticasone propionate on airway inflammation and remodeling in mild asthma: a placebo-controlled study. Am J Respir Crit Care Med 197; 155: 1864-1871.

28. Boulet LP, Turcotte H, Laviolette M, et al. Airway hyperresponsiveness, inflammation, and subepithelial collagen deposition in recently diagnosed versus longstanding mild asthma. Am J Respir Crit Care Med 2000; 162: 1308-1313.

29. Douma WR, Kerstjens HAM, Gooifer A, et al. Initial improvements in lung function and bronchial hyperresponsiveness are maintained during 5 years of treatment with inhaled beclomethasone diproprionate and terbutaline. Chest 2002; 121: 151-157.

30. Buist AS, Vollmer WM. Smoking and other risk factors. In: Murray JF, Nadel JA, eds. Textbook of 
respiratory medicine. Philadelphia, WB Saunders, 1994; 1259-1287.

31. Anthonisen NR, Connett JE, Kiley JP, et al. Effects of smoking intervention and the use of an inhaled anticholinergic bronchodilator on the rate of decline of FEV1. The Lung Health Study. JAMA 1994; 272: $1497-1505$.

32. Kanner RE and for the Lung Health Study Group. Early intervention in chronic obstructive pulmonary disease. Med Clin North Am 1996; 80: 523-547.

33. Flore MC, Bailey WC, Cohen SJ. Smoking cessation: information for specialists. AHCPR Publication No. 96-0694. Rockville, MD, US Department of Health and Human Services, Public Health Service, Agency for Health Care Policy and Research and Centers for Disease Control and Prevention, 1996.

34. The tobacco use and dependence clinical practice guideline panel, staff, and consortium representatives. A clinical practice guideline for treating tobacco use and dependence. JAMA 2000; 283: 244-254.

35. American Medical Association. Guidelines for the diagnosis and treatment of nicotine dependence: how to help patients stop smoking. Washington, DC, American Medical Association, 1994.

36. Glynn TJ, Manley MW, Pechacek TF. Physicianinflated smoking cessation program: the National Cancer Institute trials. Prog Clin Biol Res 1990; 339: $11-25$.

37. Pauwels RA, Lofdahl CG, Laitinen LA, et al. Longterm treatment with inhaled budesonide in persons with mild chronic obstructive pulmonary disease who continue smoking. European Respiratory Society Study on Chronic Obstructive Pulmonary Disease. N Engl J Med 1999; 340: 1948-1953.

38. Vestbo J, Sorensen T, Lange P, Brix A, Torre P, Viskum K. Long-term effect of inhaled budesonide in mild and moderate chronic obstructive pulmonary disease: a randomised controlled trial. Lancet 1999; 353: 1819-1823.

39. Burge PS, Calverley PM, Jones PW, Spencer S, Anderson JA, Maslen TK. Randomised, doubleblind, placebo controlled study of fluticasone propionate in patients with moderate to severe chronic obstructive pulmonary disease; the ISOLDE trial. BMJ 2000; 320: 1297-1303.

40. The Lung Health Study Research Group. Effect of inhaled triamcinolone or the decline in pulmonary function in chronic obstructive pulmonary disease. $N$ Eng J Med 2000; 343: 1902-1909.

41. Spencer S, Calverley PMA, Burge PS, Jones PW and for the ISOLDE Study Group. Health status deterioration in patients with chronic obstructive pulmonary disease. Am J Respir Crit Care Med 2001; 163: 122-128.

42. Sin DD, Tu JV. Inhaled corticosteroids and the risk of mortality and readmission in elderly patients with chronic obstructive pulmonary disease. Am J Respir Crit Care Med 2001; 164: 580-584.

43. Szefler S, Weiss S, Tonascia J, The Childhood Asthma Management Program Research Group. Long-term effects of budesonide or nedocromil in children with asthma. $N$ Engl $J$ Med 2000; 343: 1054-1063.

44. Greening AP, Ind PW, Northfield M, Shaw G. Added salmeterol versus higher-dose corticosteroid I asthma patients with symptoms on existing inhaled corticosteroid. Lancet 1994; 344: 219-224.

45. Woolcock A, Lundback B, Ringdal N, Jacques LA. Comparison of addition of salmeterol to inhaled steroids with doubling of the dose of inhaled steroid. Am J Respir Crit Care Med 1996; 153: 1481-1488.

46. O'Byrne PM, Barnes PJ, Rodriguez-Roisin R, Runnerstrom E, Sandstrom T, Svensson K, Tattersfield A. Low dose inhaled budesonide and formoterol in mild persistent asthma. The OPTIMA randomised trial. Am J Respir Crit Care Med 2001; 164: 1392-1397.

47. Pauwels RA, Lofdahl C, Postma DS, et al. For the Formoterol and Corticosteroids Establishing Therapy (FACET) International Study Group. Effect of inhaled formoterol and budesonide on exacerbations of asthma. $N$ Engl J Med 1997; 37: 1405-1411.

48. Davies L, Angus RM, Calverley PM. Oral corticosteroids in patients admitted to hospital with exacerbations of chronic obstructive pulmonary disease: a prospective randomised controlled trial. Lancet 1999; 354: 456-460.

49. Niewoehner DE, Erbland ML, Deupree RH, et al. Effect of systemic glucocorticoids on exacerbations of chronic obstructive pulmonary disease. Department of Veterans Affairs Cooperative Study Group. $N$ Engl J Med 1999; 340: 1941-1947. 